\title{
Mechanisms for Wind Direction Changes in the Very Stable Boundary Layer
}

\author{
D. FINN AND R. M. ECKMAN \\ NOAA Air Resources Laboratory, Field Research Division, Idaho Falls, Idaho \\ Z. GAO AND H. LIU \\ Laboratory for Atmospheric Research, Washington State University, Pullman, Washington
}

(Manuscript received 12 March 2018, in final form 30 July 2018)

\begin{abstract}
Large, rapid, and intermittent changes in wind direction were commonly observed in low-wind speed conditions in the very stable boundary layer during the phase 2 of the Project Sagebrush field tracer study. This paper investigates the occurrence and magnitude of these wind direction changes in the very stable boundary layer and explores their associated meteorological factors. The evidence indicates that these wind direction changes occur mainly at wind speeds of less than $1.5 \mathrm{~m} \mathrm{~s}^{-1}$ and are associated with momentum and sensible heat fluxes approaching zero in low-wind shear conditions. This results in complete vertical decoupling. They are only weakly dependent on the magnitude of turbulence. The magnitude of the wind direction changes is generally greatest near the surface, because of the greater prevalence of low wind speeds there, and decreases upward.
\end{abstract}

\section{Introduction}

Dispersion models normally assume plumes are narrowest in the stable boundary layer, consistent with the idea that the horizontal plume spread $\sigma_{y}$ is directly related to the typically smaller standard deviation $\sigma_{\theta}$ of the wind direction. This plume behavior was found to be the case during the classical Project Prairie Grass experiments (Barad 1958a,b) and a number of subsequent studies (Slade 1968). These results were widely accepted at the time (e.g., Gifford 1961; Turner 1970) and are still featured in EPA guidance documents (EPA 2000) and embedded in the implementation of traditional stabilityclass Gaussian plume models.

There is increasing awareness, however, that observed plumes in stable conditions are often much wider than would be expected if $\sigma_{\theta}$ is the dominant parameter determining plume width, especially in the very stable boundary layer (vSBL) (Mortarini et al. 2016b). Experiments in the vSBL in the 1970 s found that plumes generally subtended more than $90^{\circ}$ of arc with plumes occasionally being measured across essentially a full $360^{\circ}$ over the course of a 1 -h averaging period (Sagendorf and Dickson 1974). This study is still a

Corresponding author: D. Finn, dennis.finn@noaa.gov benchmark for plume dispersion in the vSBL in lowwind conditions (Luhar and Hurley 2012). However, these measurements did not provide any finer temporal resolution evolution of the plume during the 1-h tracer measurement period.

Recent tracer experiments in the vSBL with low wind speed $U$ found small $\sigma_{\theta}$ on time scales of $10 \mathrm{~min}$ or less that were comparable to classical results such as Project Prairie Grass (Finn et al. 2017; Finn et al. 2018). However, the measured 10-min average horizontal plume spreads were much larger than during the nighttime Project Prairie Grass experiments, often exceeding $90^{\circ}$. This was reminiscent of the Sagendorf and Dickson (1974) results and much larger than the small measured 10-min $\sigma_{\theta}$ would suggest. Finn et al. (2018) found that plumes often traveled in a relatively steady direction in very stable conditions for up to about one-half hour and then abruptly shifted several tens to over $100^{\circ}$ on time scales of $10 \mathrm{~min}$ or less. The resolution of the tracer measurements prohibited any finer breakdown of the time scales of the plume shifts. Hiscox et al. (2010) observed similar phenomena in lidar measurements of smoke plumes.

Other investigations of turbulence and meander at low $U$ in the vSBL report complementary findings (Sun et al. 2012; Mortarini et al. 2016a,b). Sun et al. (2012) show 
examples where wind directions were relatively constant over periods of 10-20 min up to more than an hour but punctuated by large shifts in excess of $100^{\circ}$ over short time intervals, sometimes less than 1-2 min. Mortarini et al. (2016b) show examples in which the wind direction was never steady for periods longer than a few minutes and exhibited nearly continuous oscillatory behavior. The wind direction changes were commonly $100^{\circ}-200^{\circ}$ in magnitude and, again, often occurred in less than 1-2 min. All of these results call into question the presumed linkage between narrow plumes and minimal $\sigma_{\theta}$ in the vSBL. They also highlight the large, rapid, and intermittent nature of these changes in wind direction in the vSBL. The changes can be oscillatory and quasi-periodic but can also be very irregular and intermittent without a discernible pattern.

Some newer plume models attempt to account for the observations of much broader horizontal plume spreads in light winds in the stable boundary layer (e.g., Cimorelli et al. 2004, 2005; Anfossi et al. 2006; Luhar 2013). Venkatram et al. (2013) attempt to model this situation by weighting plume dispersion between a random state and a Gaussian distribution. However, this is an inherently difficult problem and there is little guidance available for how the details of the observed rapid, episodic plume shifts might be captured.

This paper will examine the occurrence of these rapid, intermittent shifts in wind direction in the vSBL at low $U$, with emphasis on their magnitude and triggering mechanisms. The intent is to provide additional information that can be used for improving the modeling of plume dispersion in these conditions. It expands on the efforts by Mahrt $(2007,2008)$ and Mortarini et al. $(2016 a, b)$ for investigating and quantifying this phenomenon using a new vSBL dataset and a method focused on the changes in wind direction.

\section{Method}

The data used for this analysis were collected during October of 2016 as part of phase 2 of Project Sagebrush (PSB2), a field tracer study of plume dispersion in low $U$ conditions conducted at the Idaho National Laboratory (Finn et al. 2017, 2018). Nine nocturnal periods featuring the common presence of vSBL conditions were selected as case studies, four of which encompassed tracer release experimental periods. Continuous periods were selected that were dominated by a combination of high bulk Richardson number $\mathrm{Ri}_{b}$, high Brunt-Väisälä frequencies $N$, low nearsurface $U$, and large-magnitude negative net radiation $\mathrm{Rn}$; 10-min average $R i_{b}$ and $N$ were calculated using temperature and cup anemometer wind speed measurements from measurements at the 2- and 10-m levels of the 62-m "Grid 3"
TABLE 1. Summary of dates, times, and average $N$ and Rn for the nighttime cases selected.

\begin{tabular}{lcccc}
\hline \hline Start date & Start (MST) & End (MST) & $\begin{array}{c}N\left(\mathrm{~s}^{-1}\right) \\
(2,10 \mathrm{~m})\end{array}$ & $\mathrm{Rn}\left(\mathrm{W} \mathrm{m}^{-2}\right)$ \\
\hline 8 Oct & 1900 & 0700 & 0.129 & -61.0 \\
11 Oct & 2300 & 0700 & 0.108 & -73.6 \\
12 Oct & 1900 & 0700 & 0.091 & -60.2 \\
19 Oct & 1900 & 0700 & 0.081 & -63.4 \\
20 Oct & 1900 & 0700 & 0.105 & -58.1 \\
21 Oct & 1900 & 0700 & 0.105 & -54.2 \\
23 Oct & 1900 & 0700 & 0.096 & -43.3 \\
25 Oct & 1900 & 0700 & 0.070 & -45.8 \\
26 Oct & 2130 & 0530 & 0.093 & -51.4 \\
\hline
\end{tabular}

tower (GRI). This was one of the primary towers used during Project Sagebrush and is also part of a permanent observation network (Clawson et al. 2007). The summary of these nine periods is shown in Table 1.

The terrain is generally open and flat with a grass and sagebrush canopy. On the basis of a probabilistic analysis of wind speed profile data from the 2-, 10-, 15-, 45-, and 60-m levels on GRI, median roughness lengths $z_{0}$ of 3 and $3.8 \mathrm{~cm}$ have been estimated for southwest and northeast winds, respectively. Shallow nocturnal flows have been observed at the site. Comprehensive descriptions of all of the measurements in PSB2 can be found in Finn et al. (2015, 2016, 2017).

Two sets of sonic anemometer data were utilized in the analysis. The Field Research Division of NOAA fielded six R. M. Young Co. model Ultrasonic 81000 anemometers at the 2-, 3.7-, 9-, 16.5-, 30-, and 60-m levels on GRI. Washington State University (WSU) deployed five Campbell Scientific, Inc., model CSAT3 and CSAT3B anemometers arrayed horizontally across the study area at about $3 \mathrm{~m}$ AGL, two of which were collocated with infrared gas analyzers. The raw data were collected at $10 \mathrm{~Hz}$ and averaged to generate 1 -s averages of $U$, vertical velocity $w$, temperature, and, where available, pressure. The coordinates were not rotated because of the brevity of the averaging period, the inherent nonstationarity of the flow during the periods analyzed, and the observation that $\bar{w}$ was already essentially zero at all sonic anemometers. Two-minute averaging intervals were used to calculate $U$, the momentum fluxes $u^{\prime} w^{\prime}$ and $v^{\prime} w^{\prime}$, sensible heat flux $w^{\prime} T^{\prime}$, turbulent kinetic energy $\bar{e}$, the standard deviations of $w\left(\sigma_{w}\right)$ and temperature $\left(\sigma_{T}\right)$, and the wind shear between levels on the tower $d u / d z$ and $d v / d z$. Lowercase $u, v$, and $w$ represent the vector components of wind speed. The key measurement for this analysis is the net change in degrees of wind direction between 2-min averaging intervals $\Delta \mathrm{WD}$. The maximum $\Delta \mathrm{WD}$ was fixed at $180^{\circ}$ even if the wind direction rotated through more than $180^{\circ}$ in the 2-min interval. For example, if the wind 


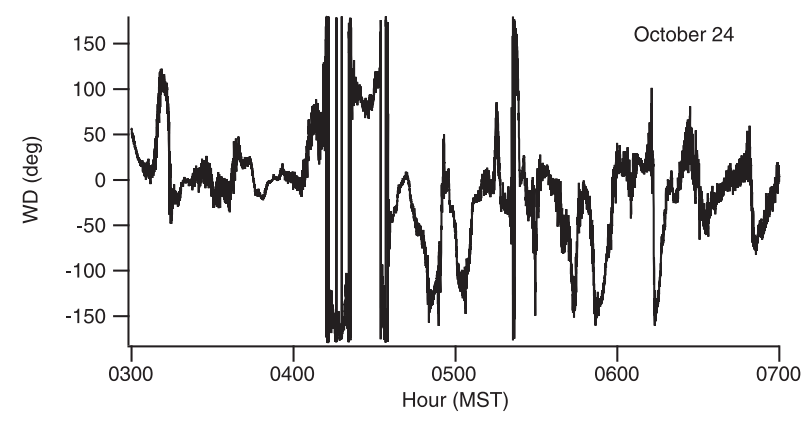

FIG. 1. Example 1-s wind direction time series from 24 Oct. The wind directions have been rotated from $0^{\circ}-360^{\circ}$ coordinates to go from $-180^{\circ}$ to $+180^{\circ}$ to minimize frequent wrapping through true north.

direction changed from $300^{\circ}$ to $40^{\circ}$, it was calculated as a $100^{\circ} \Delta$ WD. A much larger sampling using all data with $\mathrm{Ri}_{b}>0.25$ from the same set of tower sonic anemometers for the period from April 2016 to March 2018 was used to confirm whether the general picture provided by the nine case studies could be more broadly extended. An Atmospheric Systems Corporation "minisodar" located $1 \mathrm{~km}$ northeast of the tower measured 10-min average wind profiles from 30 up to $200 \mathrm{~m}$ AGL at 10 -m intervals.

\section{Results}

Table 1 summarizes the times and some aspects of the meteorological conditions for the selected nighttime periods. Unless denoted otherwise, the times shown in plots are referenced to 1900 mountain standard time (MST) as hour zero, in the evening after sundown, then past midnight to 0700 MST the next morning before sunrise, which is represented as hour 12. Dates have been assigned based on the starting date of the complete 12-h period beginning the evening of the starting date and finishing the morning of the next day. The $\mathrm{Rn}$ is based on the averages of $1-\mathrm{h}$ values covering the listed period. The $N$ represent averages based on individual 10 -min values. It is apparent from the $N$ and $\mathrm{Rn}$ averages that the selected periods were generally very stable for extended periods of time. Following Mahrt (2007), calculated values of the velocity scale representing the strength of the mesoscale flow for the PSB2 datasets were found to be similar in magnitude to that reported for CASES-99.

Figure 1 shows an example 1-s wind direction time series from the 23 October case (0300-0700 MST 24 October). This illustrates how wind direction changes can be very large and abrupt in very stable conditions. Similar to the examples shown in Sun et al. (2012) and Mortarini et al. (2016b), there is strong oscillatory behavior with large, abrupt changes in wind direction.

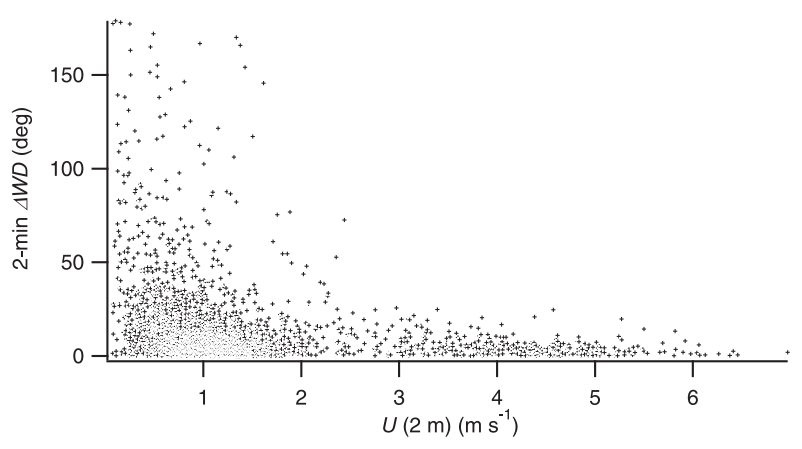

FIG. 2. Two-minute $\Delta \mathrm{WD}$ as a function of $U$ at $2 \mathrm{~m}$ AGL for all times used in nine test cases.

Figure 2 shows the 2-min $\Delta \mathrm{WD}$ as a function of $U$ at $2 \mathrm{~m}$ AGL for all time periods encompassed in Table 1. It is clear that the overall $U$ were generally $<2 \mathrm{~m} \mathrm{~s}^{-1}$ and heavily weighted toward $U<$ $1.5 \mathrm{~m} \mathrm{~s}^{-1}$. Furthermore, almost all of the large $\Delta \mathrm{WD}$ had $U<1.5 \mathrm{~m} \mathrm{~s}^{-1}$.

\section{a. Effects of turbulence and turbulent fluxes on $\Delta \mathrm{WD}$}

Figure 3 summarizes the $\Delta W D$ results as a function of the sensible heat and momentum fluxes for all the 2-min periods of Table 1 at four heights on the tower. A salient feature of these plots is how the large $\Delta \mathrm{WD}$ were, with relatively few exceptions, associated with sensible heat and momentum fluxes near zero. This was true for all levels shown and was especially the case for the momentum fluxes. Large wind shifts therefore appear to be keyed to times with limited vertical transport by turbulence in a quasi-two-dimensional turbulence field. The aggregate data from the $3 \mathrm{~m}$ AGL WSU surface array showed very similar patterns. Figure 4 confirms that the relationship of $\Delta \mathrm{WD}$ to the fluxes of sensible heat and momentum for the test cases seen in Fig. 3 holds for the more general case with $\mathrm{Ri}_{b}>0.25$ in the full 2-yr dataset. Not shown is that this relationship degrades with decreasing $\mathrm{Ri}_{b}$ with the spike in $\Delta \mathrm{WD}$ at near zero flux tending to become increasingly sparse and ill defined.

Similarly, Fig. 5 summarizes the $\Delta \mathrm{WD}$ results as a function of $\sigma_{w},(\bar{e})^{1 / 2}$, and $\sigma_{T}$ for all of the 2-min periods. It is clear that increases in $\Delta \mathrm{WD}$ tended to be associated with low turbulence with $\Delta \mathrm{WD}$ decreasing as these measures of turbulence increased and the WSU results again being similar.

Results from a subset of the case study days will now be shown to provide some details on how $\Delta \mathrm{WD}$ is affected by factors such as $U$, height, wind shear, and the presence or absence of low-level jets (LLJ). Extended periods of time from the $8,19,20,23$, and 26 October cases are shown in Figs. 6-10, respectively. 

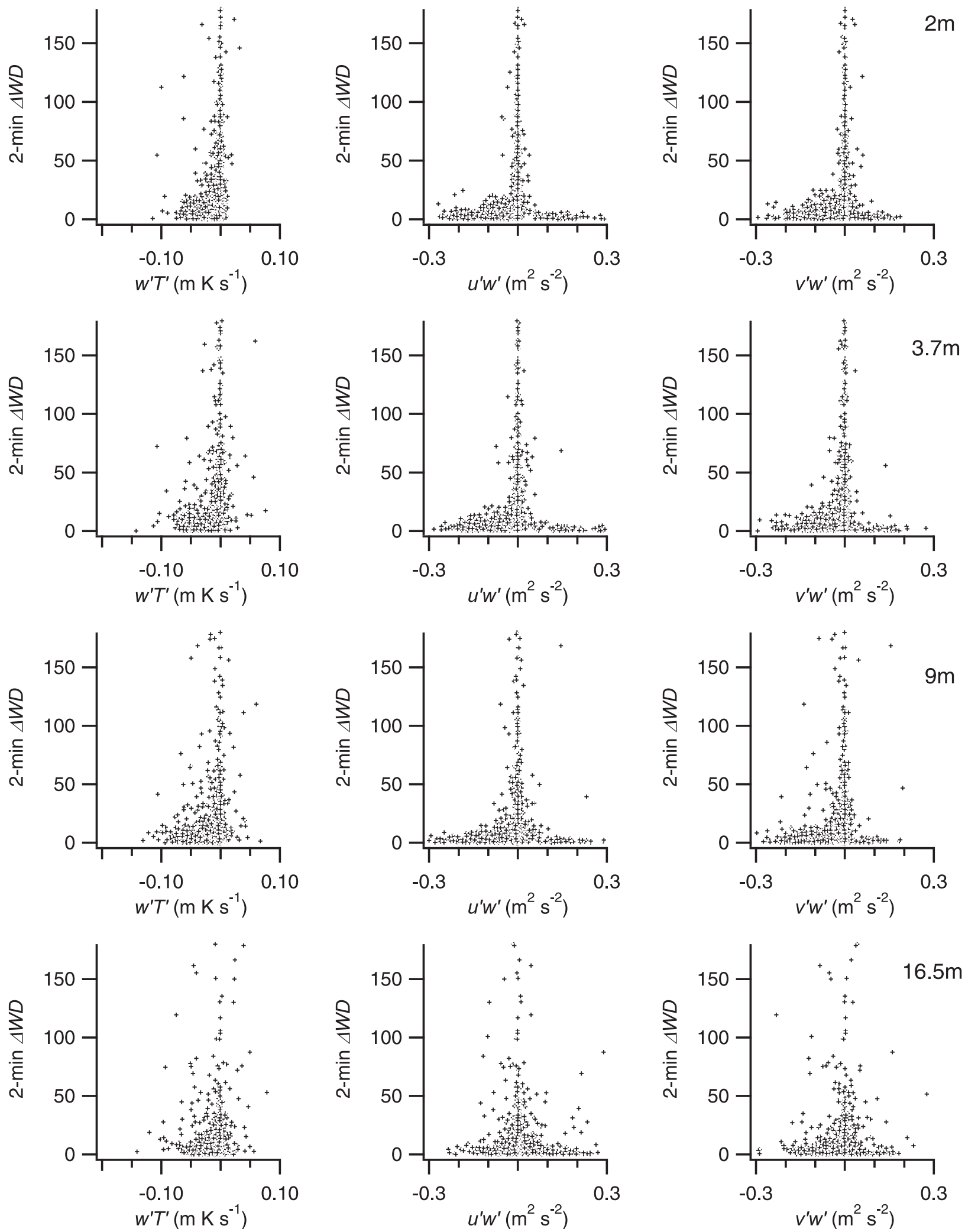

FIG. 3. $\Delta$ WD results as a function of the sensible heat and momentum fluxes for all of the 2-min periods of Table 1 at four heights on the tower. 

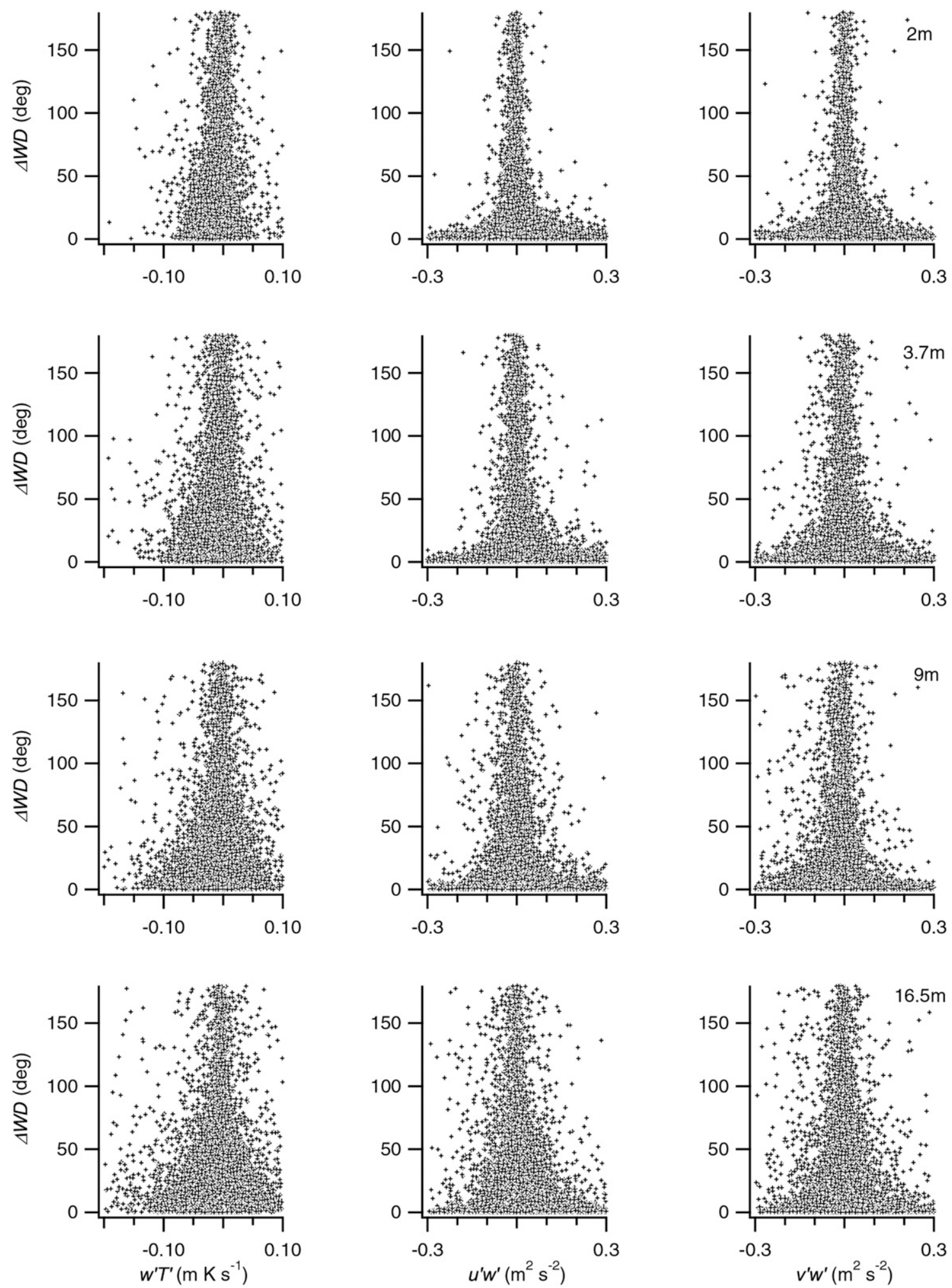

FIG. 4. $\Delta$ WD results as a function of the sensible heat and momentum fluxes for all of the 2-min periods in the 2 -yr record with $\mathrm{Ri}_{b}>0.25$ at four heights on the tower. 

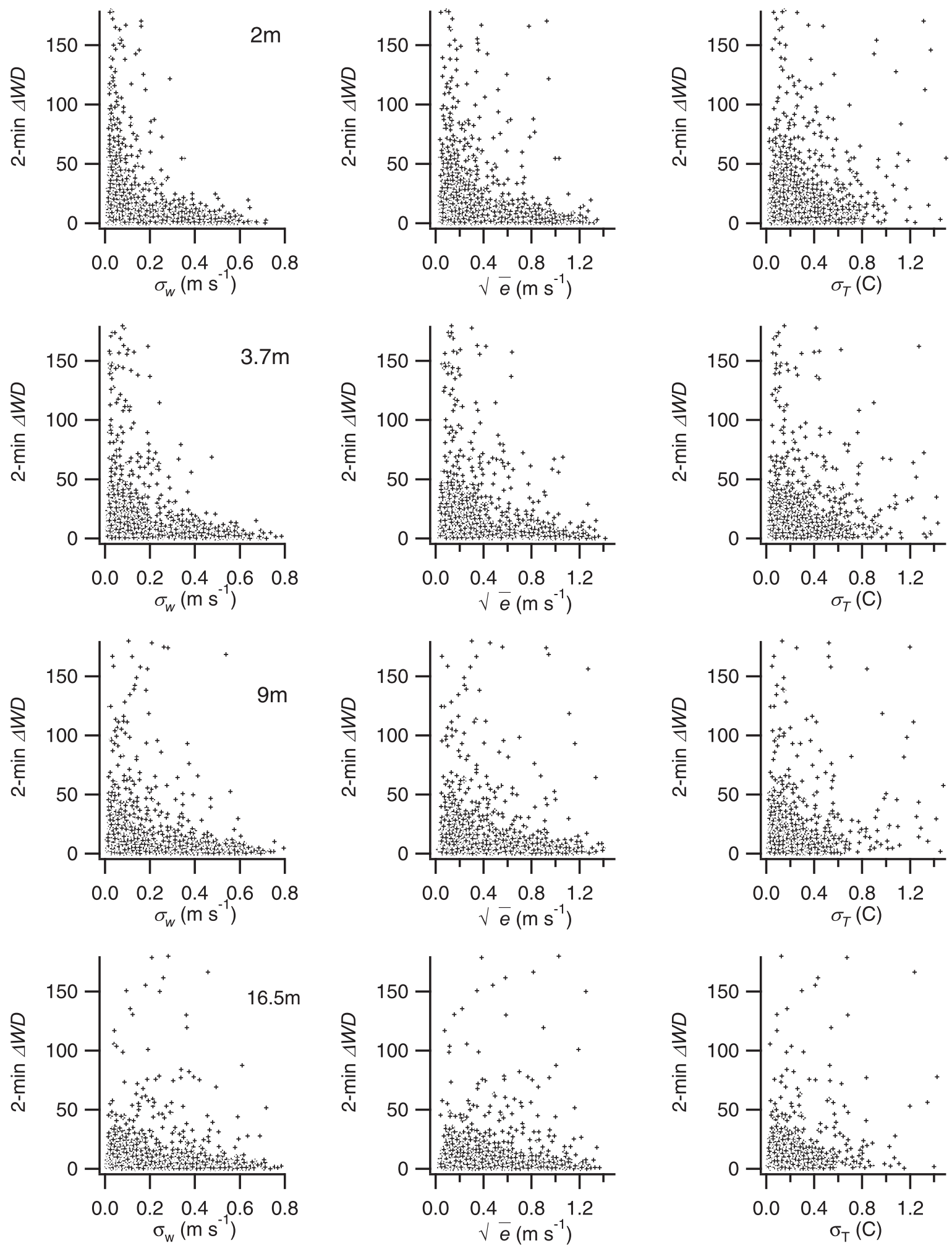

FIG. 5. $\Delta \mathrm{WD}$ results as a function of $\sigma_{w},(\bar{e})^{1 / 2}$, and $\sigma_{T}$ for all of the 2-min periods included in Table 1 . 

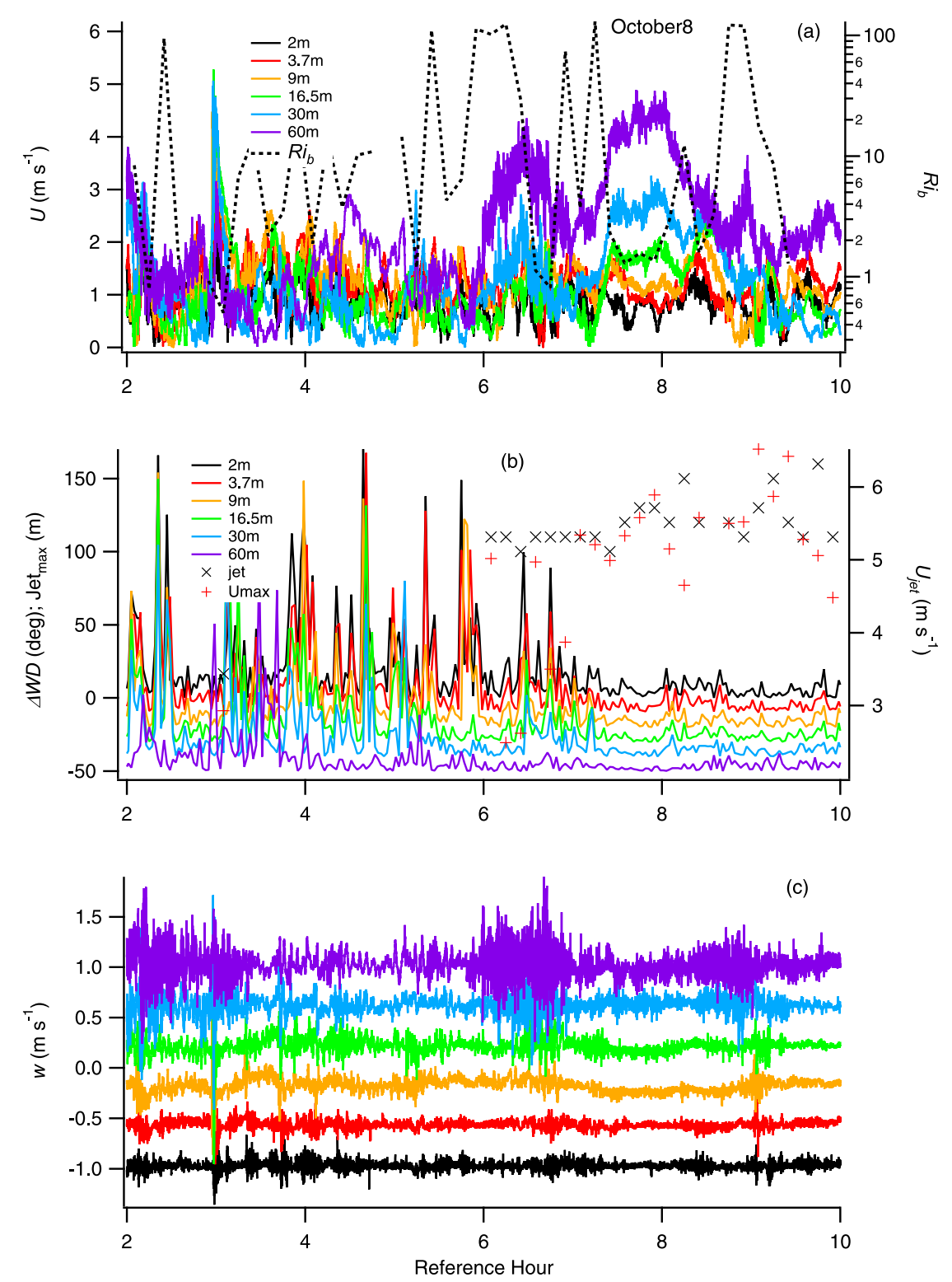

FIG. 6. GRI tower on 8 Oct: (a) 1-s $U$ and 10-min $\mathrm{Ri}_{b}$, (b) 2-min $\Delta \mathrm{WD}$ ( $-10^{\circ}$ offsets for successive heights beginning at $3.7 \mathrm{~m}$ ) and 10-min LLJ (height and $U_{\max }$ ), and (c) 1-s vertical velocity $w . \Delta \mathrm{WD}$ and $w$ traces for adjacent heights are offset for clarity by $10^{\circ}$ and $0.4 \mathrm{~m} \mathrm{~s}^{-1}$, respectively. Hour is time from 1900 MST reference.

\section{b. Effects of $U$ and height on $\Delta \mathrm{WD}$}

One of the most salient features of the data is the not unexpected association between low $U$ and increases in $\Delta \mathrm{WD}$. This could be extended over longer periods of time (e.g., Figs. 6, 8, 9, and 10) or limited to more restricted episodes (e.g., hour 6.3, Fig. 7; hours 3.8 and 8.1, Fig. 9). In a separate analysis it was found that periods exhibiting sustained periods of wind direction change in mainly one direction of rotation could be combined to form more or less continuous periods up to a half hour or more where the net change in one direction of rotation was much larger than the individual 2-min changes (up to $540^{\circ}$ total). The association between low $U$ and $\Delta \mathrm{WD}$ is consistent with the results shown in Fig. 2.

Another prominent feature of the data is that the magnitude of $\Delta \mathrm{WD}$ is related to height (Figs. $6 \mathrm{~b}, 7 \mathrm{~b}, 8 \mathrm{~b}$, $9 \mathrm{~b}$, and 10b). In most cases, large $\Delta \mathrm{WD}$ were restricted to $16.5 \mathrm{~m}$ and below and sometimes only involved the 2and $3.7-\mathrm{m}$ heights. Figures 8 and 9 show especially limited $\Delta \mathrm{WD}$ above $9 \mathrm{~m}$. Figure 11, using the full 2-yr 

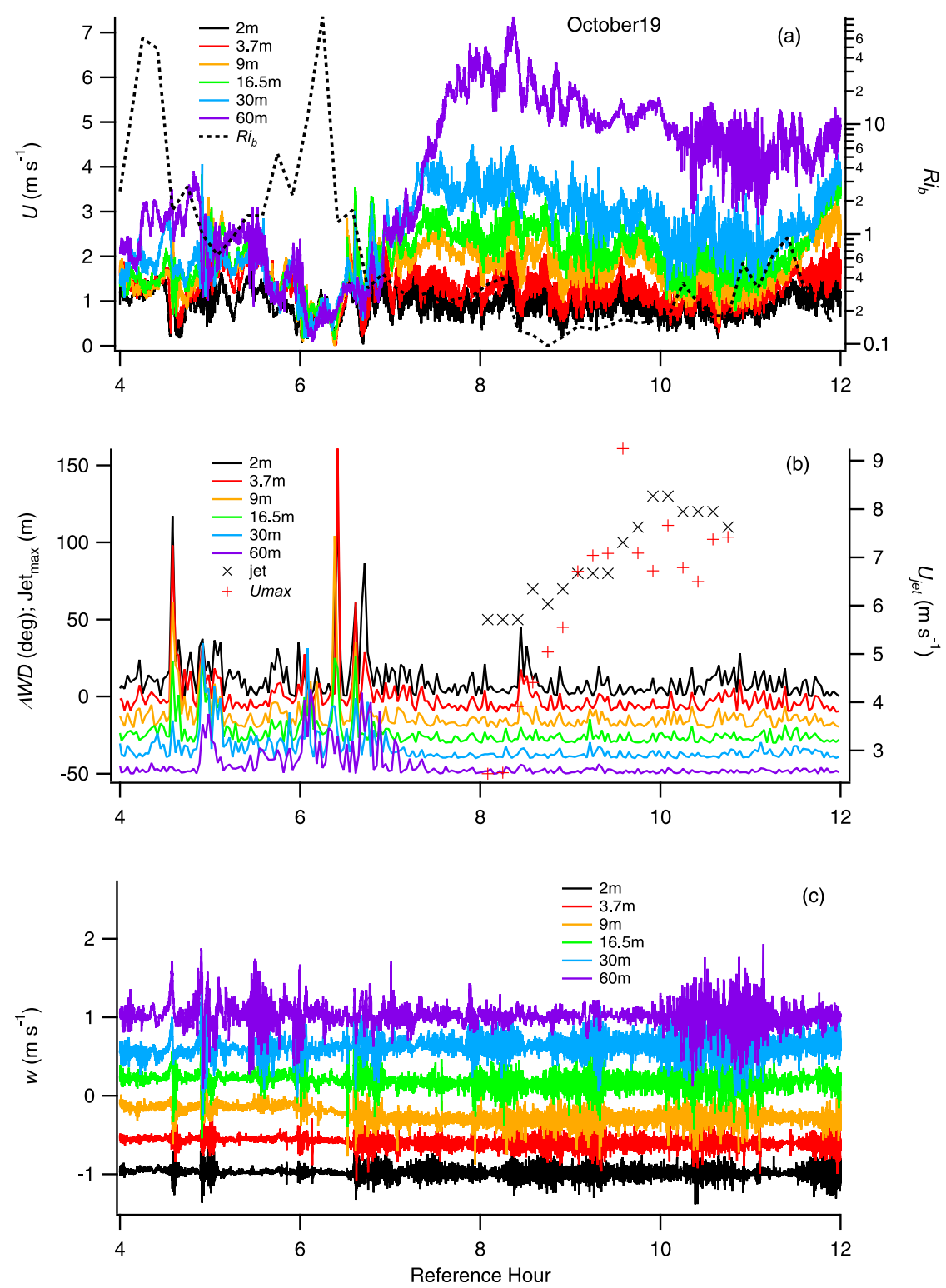

FIG. 7. As in Fig. 6, but for GRI tower on 19 Oct.

dataset with $\mathrm{Ri}_{b}>0.25$, provides a more comprehensive picture of the relationship of $\Delta \mathrm{WD}$ to height. This shows that the magnitude of $\Delta \mathrm{WD}$ is clearly related to $U$ with $\Delta \mathrm{WD}$ very similar at all heights in a given wind speed bin; however, there is a dependency of $\Delta \mathrm{WD}$ on height through the much greater occurrence of lower $U$ at lower heights. The array of WSU surface stations had binned $\Delta \mathrm{WD}$ and $U$ fractions that were very comparable to the lower heights on the GRI tower.

\section{c. Effect of wind shear on $\Delta \mathrm{WD}$}

The data also point to the role of wind shear in whether large $\Delta$ WD developed. It is apparent in Figs. 6-10 that
$\mathrm{Ri}_{b}$ was often very large. Periods with high $\mathrm{Ri}_{b}$ were more likely to be associated with periods of larger $\Delta \mathrm{WD}$ (e.g., Figs. 6, 9, and 10) and lower $\mathrm{Ri}_{b}$ were more likely to be associated with lower $\Delta$ WD (e.g., Figs. 7, 9, and 10). This was generally the case although there were exceptions (e.g., Fig. 6, hour 9). While steep temperature gradients contributed to the large $\mathrm{Ri}_{b}$, a major reason for the large $\mathrm{Ri}_{b}$ was the often small differences in wind speed between heights resulting in small denominators. As such, $\mathrm{Ri}_{b}$ is a proxy for wind shear, with lower $\mathrm{Ri}_{b}$ indicating that vertical wind shear tended to suppress $\Delta \mathrm{WD}$ and the minimization of wind shear (higher $\mathrm{Ri}_{b}$ ) tended to promote larger $\Delta \mathrm{WD}$. In some instances the wind speed 

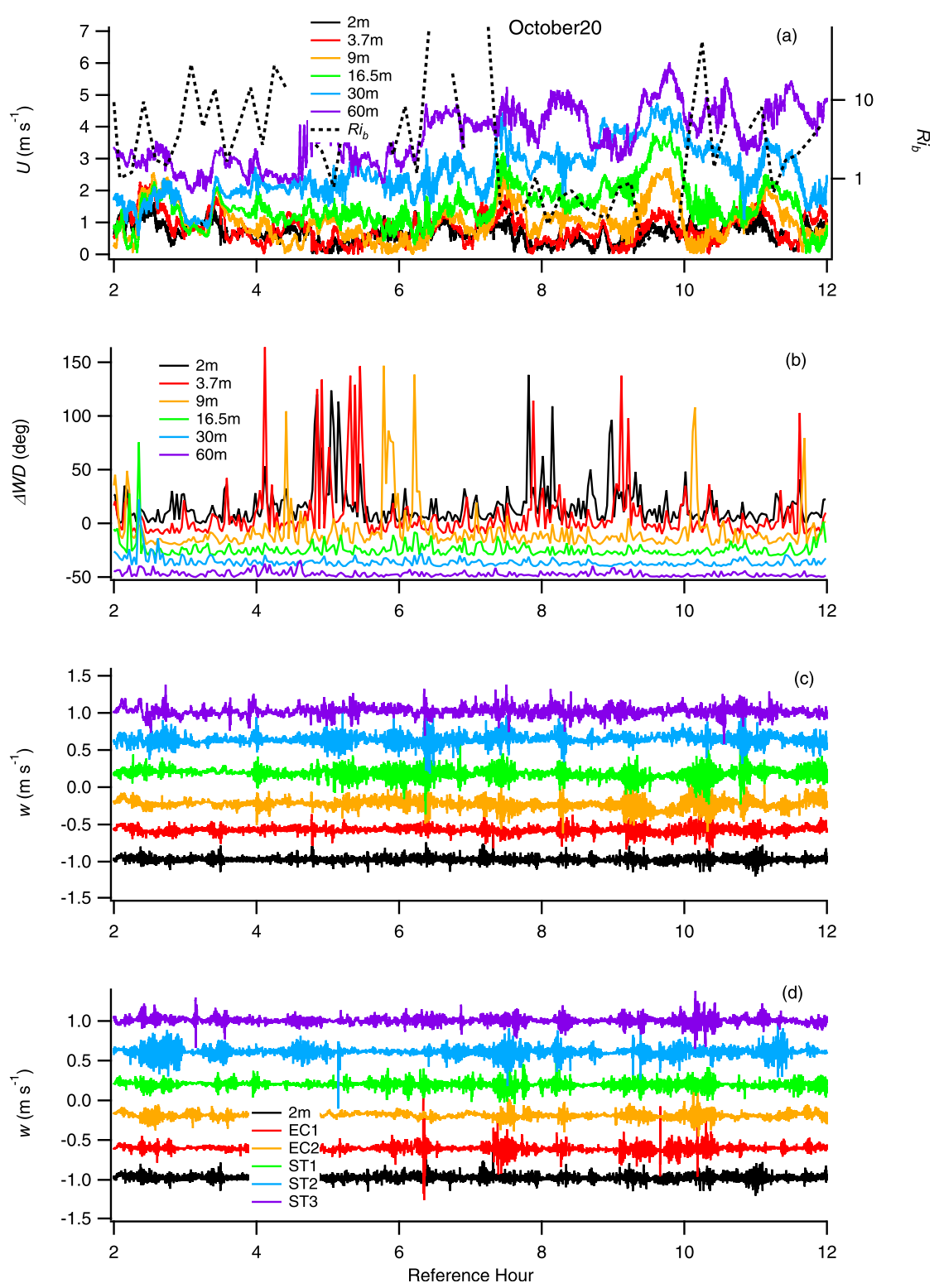

FIG. 8. GRI tower 20 Oct: (a) 1-s $U$ and 10-min $\mathrm{Ri}_{b}$, (b) 2 -min $\Delta \mathrm{WD}\left(-10^{\circ}\right.$ offsets for successive heights beginning at $3.7 \mathrm{~m}$ ) (no LLJ), (c) 1-s vertical velocity $w$, and (d) 1-s vertical velocity $w$ measured across the surface array. $\triangle \mathrm{WD}$ and $w$ traces for adjacent heights are offset for clarity by $10^{\circ}$ and $0.4 \mathrm{~m} \mathrm{~s}^{-1}$, respectively. Hour is time from 1900 MST reference.

differences in the denominator were zero resulting in occasional missing values (infinities) for $\mathrm{Ri}_{b}$ (e.g., Figs. 6, 8, and 10).

An example of wind shear effects from 23 October is shown in Fig. 12. This shows the component $d u / d z$ and $d v / d z$ wind shears between the 2- and 9-m, 9- and 16.5-m, and $16.5-$ and $30-\mathrm{m}$ heights on the tower. The magnitudes of the wind shears were generally $>0.1 \mathrm{~s}^{-1}$ until about hour 9. In comparing this result with Fig. 9 it can be seen that this was when the vertical gradient in $U$ began to decrease and $\Delta \mathrm{WD}$ began to increase.
Figure 13 aggregates the $d u / d z$ and $d v / d z$ for two levels (2 and 9; 9 and $16.5 \mathrm{~m}$ ) for all of the data in the analysis for the nine test cases. While there are exceptions, the majority of the large $\Delta W D$ were within $\pm 0.1 \mathrm{~s}^{-1}$. Levels at $9 \mathrm{~m}$ and below had the maximum magnitudes and variability in shear.

\section{d. Relationship of LLJ and $w$ to $\triangle \mathrm{WD}$}

For the case studies in Figs. 6b, 7b, 8b, 9b, and 10b, the heights of where the $U$ maxima in LLJ profiles were identified are designated by black times signs. The $U$ 

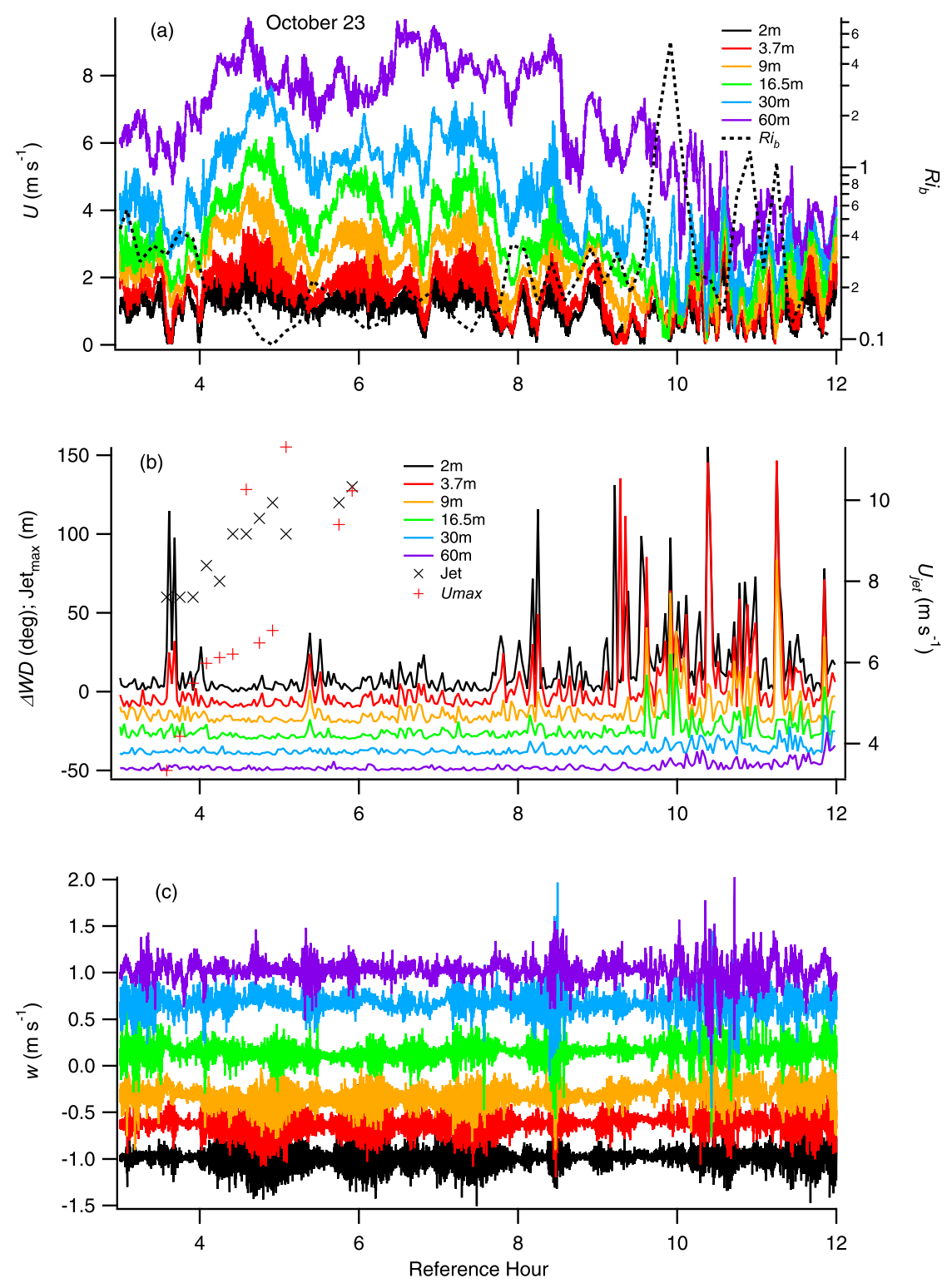

FIG. 9. As in Fig. 6, but for GRI tower on 23 Oct.

maxima associated with each height are designated with red plus signs. Most jet profiles were identified in the sodar data, although some weak jet profiles were identified in the sonic data from the tower. All of the test cases shown except 20 October (Fig. 8) had one or more periods in which an LLJ was identified.

Each case study tells its own story, but there are some recurring features. The presence of LLJ tended to promote wind shear (lower $\mathrm{Ri}_{b}$ ) and suppress $\Delta \mathrm{WD}$. There were only brief periods of notable $\Delta \mathrm{WD}$ activity in the presence of an LLJ (Fig. 6, hours 6.5-7; Fig. 9, hour 3.8). In both of these cases, the LLJ was just beginning to develop and was weak. The most prolific $\Delta \mathrm{WD}$ periods were in the absence of an
LLJ (Fig. 6, hours 2-6; parts of Fig. 7 before hour 7; Fig. 8; Fig. 9 after hour 8) with one exception in which the LLJ was very weak with $U_{\max }$ only about $3 \mathrm{~m} \mathrm{~s}^{-1}$ (Fig. 10, hours 3-5).

Figures $6 c, 7 c, 8 c, 9 c$, and $10 \mathrm{c}$ indicate that periods with maximum $\Delta \mathrm{WD}$ activity tended to be associated with relatively quiescent periods of 1-s $w$ (Fig. 6, hours 3-6; Fig. 7, approximate hours 4.7 and 6.2; Fig. 8; parts of Figs. 9 and 10). Figure 8d shows that the relative quiescence in $w$ on the tower was also present across the surface array.

However, the case studies also suggest that the interaction of $w$ with LLJ and $\Delta \mathrm{WD}$ is often complicated. The presence of LLJ was often associated with an 

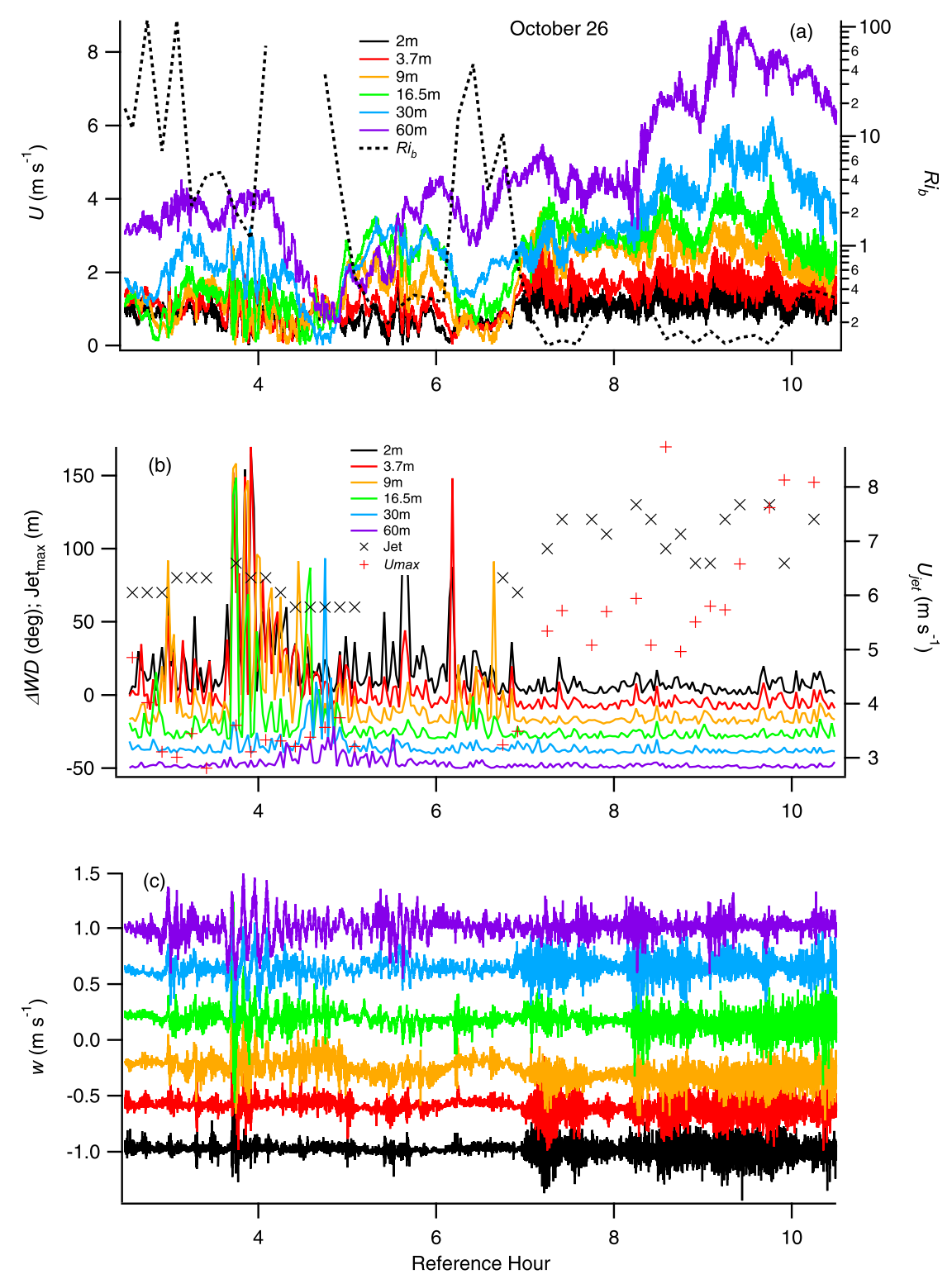

FIG. 10. As in Fig. 6, but for GRI tower on 26 Oct.

increase in $w$. Figure 10 (hours 7-11) shows consistently increased $w$ below $60 \mathrm{~m}$ with an LLJ at about 100-120 AGL. There are several examples in which a disturbance in $w$ initiated at $60 \mathrm{~m}$ was successively propagated downward to lower levels, gradually dissipating along the way (Fig. 6, approximate hours 2-3, 6.5, and 8.5; Fig. 7, hours 10-11; Fig. 9, approximate hours 8.2 and 10.2; Fig. 10, hour 3.9). In Fig. 6, the effects of the disturbances barely registered at the surface. This was in association with LLJ at about $100 \mathrm{~m}$ AGL Figures 7 and 9 are interesting cases in which it appears as if $w$ increased at $30 \mathrm{~m}$ and below in response to the onset of an LLJ at about hours 8 and 3.8, respectively, with the 60-m level being relatively unaffected. The heights of $U_{\max }$ at the beginning of the LLJ were about $50 \mathrm{~m}$ AGL and lifted with time to over $100 \mathrm{~m}$, and the magnitudes of $U_{\max }$ increased significantly. In Fig. 7, $w$ at the 60-m level became maximally affected along the underside of the jet, with the effect decreasing downward, while a similar increase in $w$ at $60 \mathrm{~m}$ is not apparent in Fig. 9. These results from Figs. 7, 9, and 10 are consistent with results of a case study of LLJ"submeso" interactions by Mortarini et al. (2018). They showed weak turbulence and large meandering associated with the nose of a jet and increased turbulence above and below the nose. 


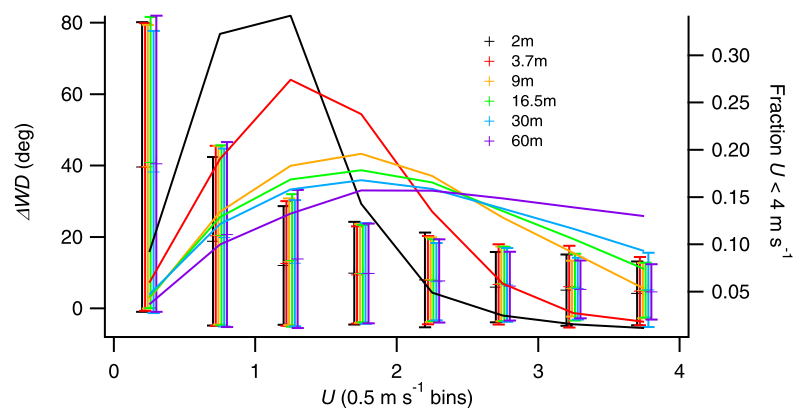

FIG. 11. Means and standard deviations of $\Delta \mathrm{WD}$ changes and fraction of wind speeds $<4 \mathrm{~m} \mathrm{~s}^{-1}$ binned in $0.5 \mathrm{~m} \mathrm{~s}^{-1}$ increments by height for all cases in the 2-yr record with $\mathrm{Ri}_{b}>0.25$.

There were a few instances in which increased $\Delta \mathrm{WD}$ was associated with increased 1 -s $w$. From hours 2 to 3 and 6 to 7 in Fig. 6, periods of enhanced $\Delta$ WD were concurrent with downward propagating disturbances in $w$. An LLJ was initiating during the latter period, although a period of high $\mathrm{Ri}_{b}$ and likely low wind shear was also present at this time. From hours 10-12 in Fig. 9, enhanced 1-s $w$ at all levels is associated with a period of increased $\Delta \mathrm{WD}$.

Another facet of the relationship among LLJ, wind speed, and $\Delta \mathrm{WD}$ is shown in Fig. 14. The periods of time with $U<1.5 \mathrm{~m} \mathrm{~s}^{-1}$ at $2 \mathrm{~m} \mathrm{AGL}$, for the test cases shown in Figs. 6-10, were grouped by whether or not an LLJ was present. Most of the LLJ were initiated with relatively weak maximum winds at lower heights but quickly increased to maxima mostly greater than $5 \mathrm{~m} \mathrm{~s}^{-1}$. The first of two LLJ in the 26 October case (Fig. 10) was an exception in that it featured persistent lower maximum $U<4 \mathrm{~m} \mathrm{~s}^{-1}$. The key point of Fig. 14 is that increases in $\Delta \mathrm{WD}$ were suppressed in the presence of LLJ, even for $U(2 \mathrm{~m})<1.5 \mathrm{~m} \mathrm{~s}^{-1}$. The exception from Fig. 10 suggests that this suppression might not be a factor with weaker LLJ when shear would presumably be reduced.

Many turbulence profiles on GRI showed localized peaks, sometimes in association with large wind direction changes between heights (not shown). These peaks were mainly isolated at the intermediate tower levels $(9,16.5$, and $30 \mathrm{~m})$. Thus, vertical shear was sometimes augmented by lateral directional shear.

\section{e. Potential role of submeso and waves influences on $\Delta \mathrm{WD}$}

The occurrence of large $\Delta$ WD was empirically heavily weighted toward low $U$, low wind shear (high $\mathrm{Ri}_{b}$ ), and low 1-s $w$ without appeal to submeso or wave-interaction mechanisms. However, the limited pressure measurements available from the WSU infrared gas analyzers as well as some of the rapid oscillatory behavior in the 1-s time series of $U$ and $w$ suggest that submeso or wave influences sometimes played a role in enhancing $\Delta \mathrm{WD}$.

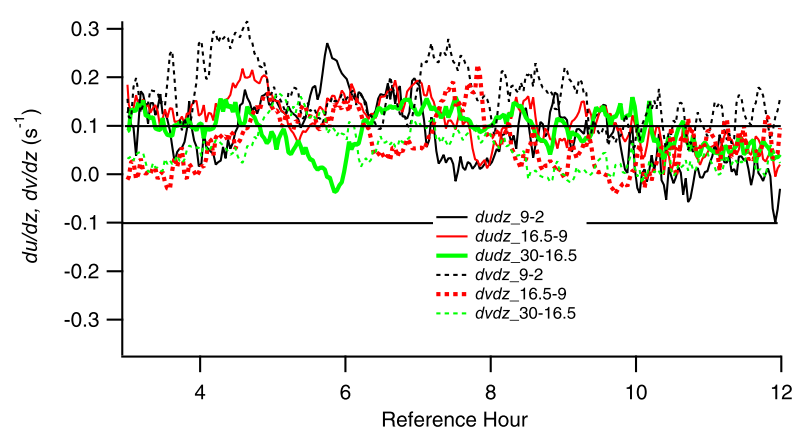

FIG. 12. Vertical wind shears $d u / d z$ and $d v / d z$ over the 2-9-, 9-16.5-, and 16.5-30-m intervals on 23 Oct. The two solid horizontal lines bound the $\pm 0.1 \mathrm{~s}^{-1}$ range.

Perhaps the most intriguing case in this regard is shown in Fig. 9 in which an extended period of abundant $\Delta$ WD near the surface from hours $8-12$ is associated with more regular, rapid oscillatory behavior in $U$. There is also strong wavelike behavior in $w$ from hour 10 to hour 11, propagating downward across all levels, and more rapid pressure oscillations between hours 8.5 and 12 (Fig. 15). It is speculated that gravity waves might have played a role in triggering the increase in $\Delta \mathrm{WD}$. Cava et al. (2017) found that the horizontal meandering they observed in their particular case study was not triggered by vertical gravity waves but instead was attributable to pressure perturbations.

Another possible example can be seen in Fig. 10 at hour 3.9. Strong wave behavior in $w$ at $60 \mathrm{~m}$ propagates to the surface at this time and is coincident with the start of a period with sharply increased $\Delta \mathrm{WD}$ activity. Near the surface, $U$ was already low and a sharp drop in $U$ at $60 \mathrm{~m}$ began a short time later ahead of the increase in $\Delta \mathrm{WD}$ at upper levels. There was a delayed increase in $\Delta \mathrm{WD}$ on the $30-$ and $60-\mathrm{m}$ levels after $\Delta \mathrm{WD}$ began to decrease near the surface. This episode appears to represent the interaction between submeso and possible gravity wave events. Also, some higher $\Delta \mathrm{WD}$ values between hours 6 and 7 in Fig. 6 suggest the influence of a submeso event with a sharp increase in $U$, especially at $30 \mathrm{~m}$ and above, the initiation of an LLJ, and increases in $w$. The increased $w$ was mainly at the 60-m level and only weakly propagated to the surface.

Some results from 23 October will be highlighted to illustrate other potential interactions (Fig. 15). An approximate 1.4 -h periodicity in $\sigma_{w}$ (and $\bar{e}$ ) can be seen with peaks at about $4.7,6.1,7.5$, and perhaps $9 \mathrm{~h}$. The maxima in $\sigma_{w}$ are approximately coincident with local minima in pressure, and vice versa. By reference to Fig. 9a, these maxima in $\sigma_{w}$ are also approximately coincident with maxima in $U$ and minima in $R i_{b}$. However, there is little in the way of increased $\Delta \mathrm{WD}$ associated 

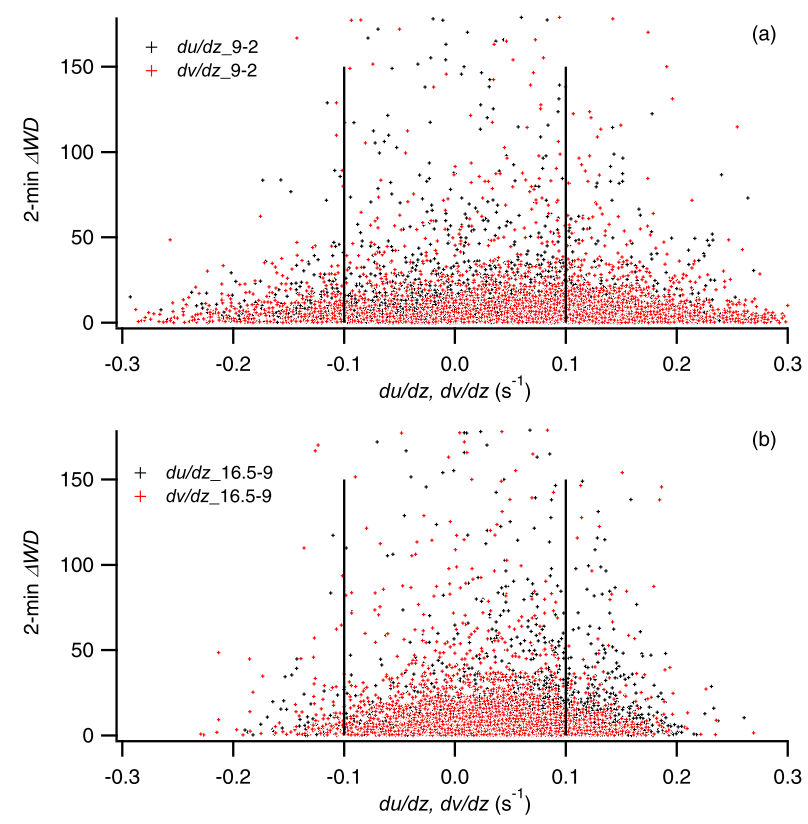

FIG. 13. Two-minute $\Delta \mathrm{WD}$ for the aggregated $d u / d z$ and $d v / d z$ wind shears for all time periods included in the test cases for the (a) 2-9- and (b) 9-16.5-m intervals.

with this (Fig. 9b). Note the higher values of $\sigma_{w}$ at station ST2, a site that often featured the highest observations of turbulence among the surface stations. It was proximal to a slight upstream terrain undulation.

\section{Discussion}

Large and rapid wind direction changes are clearly a common feature in the low $U$ vSBL. The changes can be oscillatory and quasi periodic with meandering time scales ranging from as little as $5-10 \mathrm{~min}$ (Mortarini et al. $2016 \mathrm{~b}$ ) up to $\sim 0.5 \mathrm{~h}$ or more (Hanna 1983 ; Sun et al. 2012; Mortarini and Anfossi 2015; Mortarini et al. 2016a; Finn et al. 2018). The changes can also be intermittent and highly irregular and unpredictable (Mahrt 2007, 2008). They can alternate unpredictably between periods featuring relative stationarity, periods with regular oscillatory behavior, and periods dominated by very irregular intermittency.

Previous work by Mahrt $(2007,2008)$ linked wind meander in the nocturnal boundary layer to the strength of mesoscale motions arising from various sources during weak large-scale flows. He found that a ratio of the strength of the mesoscale flow relative to the vector average wind could vary significantly and that large values of this ratio were associated with large standard deviations in wind direction. The variability of this measure was largely unpredictable but appeared to be stronger in more-complex terrain and exhibited

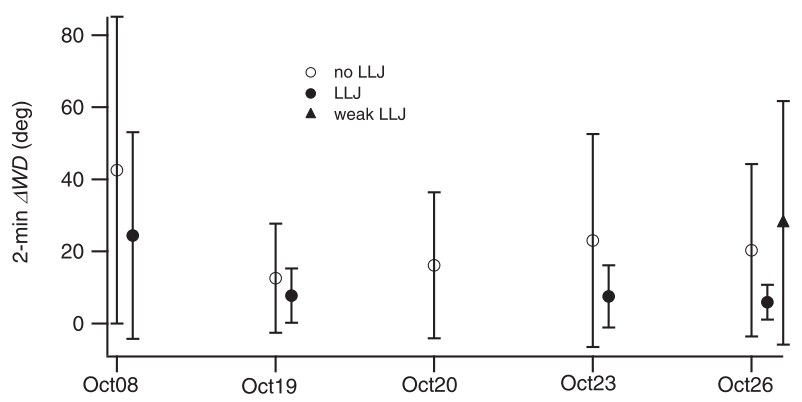

FIG. 14. Plot of the means and standard deviations of $\Delta \mathrm{WD}$ at $2 \mathrm{~m}$ AGL for LLJ and non-LLJ periods with $U<1.5 \mathrm{~m} \mathrm{~s}^{-1}$ for the test cases shown in Figs. 6-10.

some correspondence with large vertical shear of wind direction.

Sun et al. (2012) have proposed a 3-regime nocturnal turbulence scheme that partly addresses the wind direction observations. In regime $1, U$ is less than a critical threshold value, turbulence is very weak, and wind directions are more prone to oscillatory behavior. The threshold value is near $1.5 \mathrm{~m} \mathrm{~s}^{-1}$ near the surface and increases with height (e.g., $3 \mathrm{~m} \mathrm{~s}^{-1}$ at $5 \mathrm{~m} ; \sim 4.3 \mathrm{~m} \mathrm{~s}^{-1}$ at $10 \mathrm{~m} \mathrm{AGL}$ ). In regime $2, U$ is greater than the threshold, turbulence is generated mainly by bulk shear, and wind direction oscillations are suppressed. Variations in $U$ back and forth below and above the threshold could trigger or suppress, respectively, large changes in wind direction in an irregular manner (their transition A). Much of the data included in the present analysis would be assigned to their regime 1. From the Sun et al. (2012) results, Sun et al. (2015) developed a scheme describing potential mechanisms for the interactions between waves and turbulence that could contribute to large, abrupt wind direction changes.

Oettl et al. (2005) and Goulart et al. (2007) suggest meandering is a special case of the Navier-Stokes equation at low $U$ in which "equilibrium between Coriolis force and pressure gradient generates a solution that shows oscillatory characteristics." Thus an increase in the horizontal pressure gradient inhibits meandering. The comparison of LLJ with non-LLJ results in Fig. 14 is consistent with this idea. Other work has found that the frequency of meander or near meander increased with a decrease in $U$ or increase in stability based upon the ratio between a parameter for the large-scale meandering time scale and a parameter for the smallscale turbulence time scale at $U<1.5 \mathrm{~m} \mathrm{~s}^{-1}$ (Mortarini et al. 2016a,b).

The work presented here suggests that most of the rapid, irregular changes in wind direction occur over short periods, often just a few minutes long. These are triggered by the collapse of the turbulent fluxes resulting 

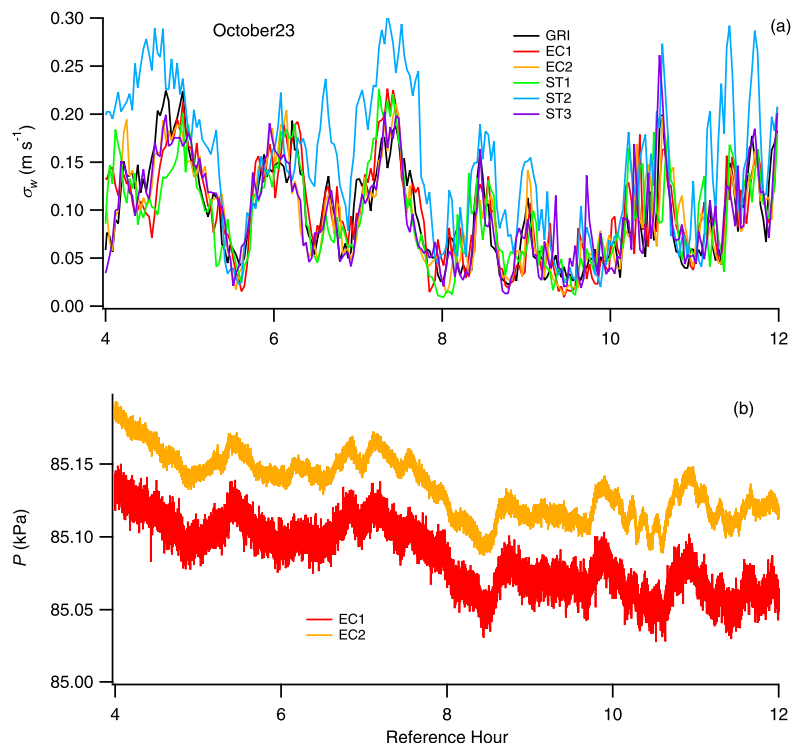

FIG. 15. Time series of (a) 2-min average $\sigma_{w}$ and (b) 1-s pressure at surface stations for 23 Oct.

in complete vertical decoupling. There are several potential mechanisms that could sustain the intermittent turbulent fluxes and mixing and, consequently, coupling (Mahrt 2014; Sun et al. 2015; Mortarini et al. 2016b; Lan et al. 2018). Failing that, any turbulent eddies generated are localized and have small enough vertical scales such that they do not interact with the surface (Mortarini et al. 2016b; Lan et al. 2018). This has consequences on the validity of Monin-Obukhov similarity theory in these conditions (Hicks et al. 2014; Liang et al. 2014; Trini Castelli et al. 2014).

These periods of rapid, irregular wind direction change can be sustained over longer periods and rotate through more than $360^{\circ}$. This work also supports a nearsurface value $U \approx 1.5 \mathrm{~m} \mathrm{~s}^{-1}$ as a critical threshold value. It is likely that the irregular, intermittent regime is a common state of the vSBL ( $U$ at $2 \mathrm{~m}<1.5 \mathrm{~m} \mathrm{~s}^{-1}$ ) with respect to wind direction changes in the absence of some forcing mechanism that imposes some sort of periodicity. Lan et al. (2018) also found the threshold velocity has a height dependency with a value of about $1.6 \mathrm{~m} \mathrm{~s}^{-1}$ near the surface. Consistent with the results reported here, they identified a layer near the surface where large wind direction changes were frequent but with relatively constant wind directions above.

\section{Conclusions}

This paper investigated the occurrence and magnitude of rapid, intermittent wind direction changes in the very stable boundary layer. The evidence indicates that these large wind direction changes occur mainly at wind speeds less than $1.5 \mathrm{~m} \mathrm{~s}^{-1}$ when momentum and sensible heat fluxes approach zero in conditions of low wind shear conditions. The magnitude of the wind direction changes is greatest near the surface, mainly because of the prevalence of lower wind speeds there, and generally decreases rapidly upward. The presence of LLJ suppresses the incidence of these wind direction changes. The large wind direction changes occur mainly in weakly turbulent conditions but are otherwise largely independent of the magnitude of turbulence. There is some evidence from the analysis that submeso and wave interactions played a role in triggering some episodes of rapid, intermittent wind direction changes and increased $\Delta \mathrm{WD}$.

Acknowledgments. We acknowledge Kirk Clawson, Roger Carter, Jason Rich, Shane Beard, Brad Reese, Donna Davis, Matt Brewer, and Devin Clinger from the Field Research Division of NOAA and Justine Missik and Raleigh Grysko from the Laboratory for Atmospheric Research at Washington State University for their contributions to the field campaign. Participation by Washington State University was supported by National Science Foundation AGS under Grant 1419614. We also thank the reviewers, who provided several comments that helped to improve the paper. The scientific results and conclusions, as well as any views or opinions expressed herein, are those of the author(s) and do not necessarily reflect the views of NOAA or the Department of Commerce.

\section{REFERENCES}

Anfossi, D., S. Alessandrini, S. Trini Castelli, E. Ferrero, D. Oettl, and G. Degrazia, 2006: Tracer dispersion simulation in low wind speed conditions with a new 2D Langevin equation system. Atmos. Environ., 40, 7234-7245, https://doi.org/10.1016/ j.atmosenv.2006.05.081.

Barad, M. L., Ed., 1958a: Project Prairie Grass, a field program in diffusion. Geophysical Research Papers, No. 59, Vol. I, Air Force Cambridge Research Center Rep. AFCRC-TR-58-235(I), 280 pp., http://www.harmo.org/ jsirwin/PGrassVolumeI.pdf.

— 1958b: Project Prairie Grass, a field program in diffusion. Geophysical Research Papers, No. 59, Vol. II, Air Force Cambridge Research Center Rep. AFCRC-TR-58-235(II), 209 pp., http://www.harmo.org/jsirwin/PGrassVolumeII.pdf.

Cava, D., L. Mortarini, U. Giostra, R. Richiardone, and D. Anfossi, 2017: A wavelet analysis of low-wind-speed submeso motions in a nocturnal boundary layer. Quart. J. Roy. Meteor. Soc., $\mathbf{1 4 3}$, 661-669, https://doi.org/10.1002/qj.2954.

Cimorelli, A. J., and Coauthors, 2004: AERMOD: Description of model formulation. U.S. Environmental Protection Agency Rep. EPA-454/R-03-004, 91 pp., https://www3.epa.gov/scram001/ 7thconf/aermod/aermod_mfd.pdf.

— , and Coauthors, 2005: AERMOD: A dispersion model for industrial source applications. Part I: General model formulation 
and boundary layer characterization. J. Appl. Meteor., 44, 682693, https://doi.org/10.1175/JAM2227.1.

Clawson, K. L., R. M. Eckman, N. F. Hukari, J. D. Rich, and N. R. Ricks, 2007. Climatography of the Idaho National Laboratory. 3rd ed. NOAA Air Resources Laboratory Tech. Memo. OAR ARL-259, 142 pp., https://doi.org/10.7289/V500003F.

EPA, 2000: Meteorological monitoring guidance for regulatory modeling applications. U.S. Environmental Protection Agency Rep. EPA-454/R-99-005, 171 pp., https://www3.epa.gov/scram001/ guidance/met/mmgrma.pdf.

Finn, D., and Coauthors, 2015: Project SageBrush phase 1. NOAA Air Resources Laboratory Tech. Memo. OAR ARL-268, 338 pp., https://doi.org/10.7289/V5VX0DHV.

_, K. L. Clawson, R. M. Eckman, H. Liu, E. S. Russell, Z. Gao, and S. Brooks, 2016: Project Sagebrush: Revisiting the value of the horizontal plume spread parameter $\sigma_{y}$.J. Appl. Meteor. Climatol., 55, 1305-1322, https://doi.org/10.1175/JAMC-D-150283.1.

—- and Coauthors, 2017: Project Sagebrush phase 2. NOAA Air Resources Laboratory Tech. Memo. OAR ARL-275, 392 pp., https://doi.org/10.7289/V5/TM-OAR-ARL-275.

- , R. G. Carter, R. M. Eckman, J. D. Rich, Z. Gao, and H. Liu, 2018: Plume dispersion in low-wind-speed conditions during Project Sagebrush phase 2 with emphasis on concentration variability. Bound.-Layer Meteor., 169, 67-91, https://doi.org/ 10.1007/s10546-018-0360-8.

Gifford, F. A., 1961: Use of routine meteorological observations for estimating atmospheric dispersion. Nucl. Saf., 2, 47-51.

Goulart, A., G. Degrazia, O. Acevedo, and D. Anfossi, 2007: Theoretical considerations of meandering wind in simplified conditions. Bound.-Layer Meteor., 125, 279-287, https://doi.org/ 10.1007/s10546-007-9179-4.

Hanna, S. R., 1983: Lateral turbulence intensity and plume meandering during stable conditions. J. Climate Appl. Meteor., 22, 1424-1430, https://doi.org/10.1175/1520-0450(1983) 022<1424:LTIAPM $>2.0 . \mathrm{CO} ; 2$.

Hicks, B. B., W. R. Pendergrass, C. A. Vogel, R. N. Keener, and S. M. Leyton, 2014: On the micrometeorology of the southern Great Plains 1: Legacy relationships revisited. Bound.-Layer Meteor., 151, 389-405, https://doi.org/10.1007/s10546-013-9902-2.

Hiscox, A. L., D. R. Miller, and C. J. Nappo, 2010: Plume meander and dispersion in a stable boundary layer. J. Geophys. Res., 115, D21105, https://doi.org/10.1029/2010JD014102.

Lan, C., H. Liu, D. Li, G. G. Katul, and D. Finn, 2018: Distinct turbulence structures in stable boundary layers with two coupling states. J. Geophys. Res. Atmos., 123, 7839-7854, https://doi.org/10.1029/2018JD028628.

Liang, J., L. Zhang, Y. Wang, X. Cao, Q. Zhang, H. Wang, and B. Zhang, 2014: Turbulence regimes and the validity of similarity theory in the stable boundary layer over complex terrain of the Loess Plateau, China. J. Geophys. Res. Atmos., 119, 6609-6021, https://doi.org/10.1002/2014JD021510.

Luhar, A. K., 2013: Lagrangian particle modeling of dispersion in light winds. Lagrangian Modeling of the Atmosphere, Geophys. Monogr., Vol. 200, Amer. Geophys. Union, 37-51.

- and P. J. Hurley, 2012: Application of a coupled prognostic model to turbulence and dispersion in light-wind stable conditions, with an analytical correction to vertically resolved concentrations near the surface. Atmos. Environ., 51, 56-66, https://doi.org/10.1016/j.atmosenv.2012.01.046.
Mahrt, L., 2007: Weak-wind mesoscale meandering in the nocturnal boundary layer. Environ. Fluid Mech., 7, 331-347, https:// doi.org/10.1007/s10652-007-9024-9.

_ 2008: Mesoscale wind direction shifts in the stable boundarylayer. Tellus, 60A, 700-705, https://doi.org/10.1111/j.1600-0870. 2008.00324.x.

- 2014: Stably stratified atmospheric boundary layers. Annu. Rev. Fluid Mech., 46, 23-45, https://doi.org/10.1146/annurevfluid-010313-141354.

Mortarini, L., and D. Anfossi, 2015: Proposal of an empirical velocity spectrum formula in low-wind speed conditions. Quart. J. Roy. Meteor. Soc., 141, 85-97, https://doi.org/10.1002/qj.2336.

- , S. Maldaner, L. P. Moor, M. B. Stefanello, O. Acevedo, G. Degrazia, and D. Anfossi, 2016a: Temperature autocorrelation and spectra functions in low-wind meandering conditions. Quart. J. Roy. Meteor. Soc., 142, 1881-1889, https:// doi.org/10.1002/qj.2796.

—, M. Stefanello, G. Degrazia, D. Roberti, S. Trini Castelli, and D. Anfossi, 2016b: Characterization of wind meandering in low-wind-speed conditions. Bound.-Layer Meteor., 161, 165182, https://doi.org/10.1007/s10546-016-0165-6.

—, D. Cava, U. Giostra, O. Acevedo, L. G. Nogueira Martins, P. E. Soares de Oliveira, and D. Anfossi, 2018: Observations of submeso motions and intermittent turbulent mixing across a low level jet with a 132-m tower. Quart. J. Roy. Meteor. Soc., 144, 172-183, https://doi.org/10.1002/qj.3192.

Oettl, D., A. Goulart, G. Degrazia, and D. Anfossi, 2005: A new hypothesis on meandering atmospheric flows in low wind speed conditions. Atmos. Environ., 39, 1739-1748, https://doi.org/10.1016/ j.atmosenv.2004.11.034.

Sagendorf, J. F., and C. R. Dickson, 1974: Diffusion under low windspeed, inversion conditions. NOAA Tech. Memo. ERL ARL-52, 89 pp., http://www.arl.noaa.gov/documents/reports/ ARL-52.pdf.

Slade, D. H., Ed., 1968: Meteorology and Atomic Energy. U.S. Atomic Energy Commission Office of Information Services Rep. TID-24190, 445 pp., https://www.orau.org/ptp/PTP\% 20Library/library/Subject/Meteorology/meteorology\%20and \%20atomic\%20energy.pdf.

Sun, J., L. Mahrt, R. Banta, and Y. L. Pichugina, 2012: Turbulence regimes and turbulence intermittency in the stable boundary layer during CASES-99. J. Atmos. Sci., 69, 338-351, https://doi.org/ 10.1175/JAS-D-11-082.1.

- — C. Nappo, and D. Lenschow, 2015: Wind and temperature oscillations generated by wave-turbulence interactions in the stably stratified boundary layer. J. Atmos. Sci., 72, 1484 1503, https://doi.org/10.1175/JAS-D-14-0129.1.

Trini Castelli, S., S. Falabino, L. Mortarini, E. Ferrero, R. Richiardone, and D. Anfossi, 2014: Experimental investigation of surface-layer parameters in low-wind speed conditions in a suburban area. Quart. J. Roy. Meteor. Soc., 140, 2023-2036, https://doi.org/10.1002/qj.2271.

Turner, D. B., 1970: Workbook of atmospheric diffusion estimates. U.S. Environmental Protection Agency Office of Air Programs Publ. AP-26, 84 pp., http://www.dot.ca.gov/newtech/ researchreports/1969-1970/70-07.pdf.

Venkatram, A., M. G. Snyder, D. K. Heist, S. G. Perry, W. B. Petersen, and V. Isakov, 2013: Re-formulation of plume spread for near-surface dispersion. Atmos. Environ., 77, 846855, https://doi.org/10.1016/j.atmosenv.2013.05.073. 